\title{
A Qualitative Exploration of Racial and Ethnic Differences in Cost of Care Conversations Among Older Adults
}

Kyaien Oquinn Conner ( $\boldsymbol{\nabla}$ koconner@usf.edu )

University of South Florida https://orcid.org/0000-0003-4278-861X

Jaqueline Wiltshire

University of South Florida

Edlin Colato Garcia

University of South Florida

Barbara Langland-Orban

University of South Florida

\section{Erica Anderson}

University of South Florida

Iraida Carrion

University of South Florida

Amber Goodman

Florida International University

Ashley Goodman

Florida International University

Research article

Keywords: Cost-of-care, healthcare, racial differences

Posted Date: August 28th, 2020

DOI: https://doi.org/10.21203/rs.3.rs-55371/v1

License: (1) (1) This work is licensed under a Creative Commons Attribution 4.0 International License.

Read Full License 


\section{Abstract}

Background: The rapidly growing racially diverse, aging population in the United States is presenting unique challenges for our social, economic, and healthcare systems. Rising health care costs, increased patient cost-sharing, and limited financial resources make this generation of older Americans susceptible to large medical bills or debt which disproportionally impacts older racial/ethnic minorities. Cost-of-care $(\mathrm{CoC})$ conversations between patients and doctors is one recommended approach to containing health care costs and alleviating patients' financial burden of care.

Methods: The current study used focus group methodology to qualitatively explore the contextual factors that influence $\mathrm{CoC}$ conversations in a diverse sample of older adults $(\mathrm{N}=27)$.

Results: Three focus groups were held with White $(n=10)$, African American $(n=9)$ and Hispanic/Latino $(n=8)$ participants. Thematic analysis yielded four broad themes. Results suggest that $\mathrm{CoC}$ conversations are not occurring with physicians, although conversations are occurring with dentists and pharmacists. Contributors to $\mathrm{CoC}$ conversations included positive provider affect, rapport/relationship building, and communication. Barriers included: new age physicians, lack of physician training, wait time, lack of focus on the patient, language, provider preferences, fear of physicians, and religion; however, there was little similarity across racial/ethnic groups.

Conclusions: The results of this qualitative study suggest that cost-of-care conversations are not occurring between providers and their patients. Several barriers, contributors, and solutions to cost-of-care conversations were identified by focus group participants, which have important implications for the field, and are addressed in this manuscript.

\section{Background And Introduction}

Rising healthcare costs are a threat to the well-being of older Americans (Briesacher et al., 2010; Jacobson et al., 2017; Osborn et al., 2014; Wiltshire et al., 2016; Zilcha \& Schneier, 2012). Approximately one in five older Americans skip needed care due to costs (Osborn et al., 2014), which contributes to adverse health outcomes including heart failure (Rahimi et al., 2007). Older adults report difficulty paying for basic living necessities, being contacted by collection agencies, putting off major purchases, using savings, and borrowing money because of medical bills (Cubanski et al., 2014; Wiltshire et al., 2016). Thus, older adults with difficulties paying for care are likely to be impoverished and live sicker lives (Attanasio et al., 2003; DeNardi et al., 2010; Gould \& Cooper, 2013; Wallace et al., 2017). Older racial/ethnic minorities may be disproportionately impacted by unaffordable medical bills because they tend to have higher rates of chronic conditions, have higher out-of-pocket expenses, and fewer financial resources than their White counterparts (Cubanski et al., 2014; Meschede et al., 2010).

Cost-of-care conversations between patients and doctors is one recommended approach to controlling health care costs and alleviating patients' financial burden of care (Hardee et al., 2005; Hunter et al., 2016; Riggs \& Ubel, 2014). Such conversations have been shown to lead doctors to switch to lower cost 
treatment options (Schmittdiel et al., 2010; Wilson et al., 2007). Patients also believed that these conversations helped to reduce their expenses (Hunter et al., 2016). Studies show that $70-80 \%$ of elderly patients want to discuss cost-of-care with their doctors; however, only $30-40 \%$ report having these conversations (Hunter et al., 2016; Riggs \& Ubel, 2014; Schmittdiel et al., 2010). Research also indicates that some patients who want to discuss cost-of-care would prefer that their doctors initiate these conversations (Hardee et al., 2005). It is unclear why these conversations are not occurring more frequently among high cost patients such as older adults.

Research among Americans aged 19-64 indicate that racial/ethnic minorities and low-income patients are less likely than their counterparts to trust their doctor to inform them about the costs of different treatment options (Long et al., 2017). Patients also may not know enough about their insurance coverage and out-of-pocket costs related to their healthcare to discuss cost-of-care. Medicare beneficiaries, especially African Americans and Hispanics. These populations often lack the skills and knowledge to successfully use their health insurance benefits and make decisions concerning their care (McCormack et al., 2009; Paez et al., 2014). There is little information on how and whether cost-of-care conversations are occurring among elderly racial and ethnic minorities, who are currently disproportionately burdened by health care costs and bills (Chen et al., 2011; Schoenberg et al., 2007; Wiltshire et al., 2016). To address this gap in the literature, the current study used focus group methodology to qualitatively explore the contextual factors that influence cost-of-care conversations in a diverse sample of older adults residing in the Tampa, Florida area.

\section{Methods}

\section{Study Sample}

The focus group sample was part of a larger study exploring healthcare affordability and cost-of-care conversations among older adults. A purposive sample $(\mathrm{N}=27)$ of older adults (age 65 and over) engaged in focus groups to explore the factors that influence cost-of-care conversations. Participants were recruited at three senior activity centers that primarily serve only Blacks or Hispanics, or Whites. Recruitment was facilitated by the project coordinator and lead contacts from the Senior Connection Center (the local Area Agency on Aging, which serves adults aged $\geq 60$ in the Tampa Bay area). Lead contacts at eight separate senior activity centers informed individuals of the research purpose. Interested participants were screened into the project based upon the following eligibility requirements: Englishspeaking, age $\geq 65$, and Medicare recipient. Individuals were determined ineligible if: 1 ) they were under 65 years of age, 2) did not self-identified as non-Hispanic White, non-Hispanic Black, or Hispanic, or 3 ) appeared to be cognitively impaired. Individuals interested, who screened as eligible, were asked to sign up on a sheet with the activity center's lead contact. The first ten to sign up per site (3 host locations) were invited to participate in the focus groups. Three participants dropped out due to health reasons, leaving us with a total sample of $\mathrm{N}=27$. Focus group participants received a $\$ 10$ gift card as an incentive. Study protocol Pro00036171 received approval from our University's Institutional Review Board. 


\section{Focus Groups}

Three focus groups were conducted in conference rooms at facilities affiliated with the Senior Connection Center. Based on Krueger and Casey's recommendation (2000), the three focus groups were stratified by race including Whites $(n=10)$, African Americans/Blacks $(n=9)$, and Hispanic/Latinos $(n=8)$. Having separate focus groups for each racial/ethnic group was important for this project to ensure individuals could talk openly about race or ethnicity specific challenges. A trained moderator with either a Ph.D or Master's degree, of the same racial/ethnic background, both were women, conducted the focus groups. Participants had no relationship with moderators before the focus groups. Focus groups were conducted using a structured interview, consisting of eight open-ended cost-of-care conversation questions (see table 1) and began with moderators introducing themselves and reasons why this topic is important and of interest to them professionally and personally. Topics explored in each group were focused on their perceptions regarding the cost of health care, including perceived challenges and recommendations. Only research team members and participants were present during the focus groups, and all three focus groups met once for approximately 45-60 minutes.

\section{Table 1: Focus Group Questionnaire}

1. What comes to mind when you think about the cost of healthcare? (Probes: insured vs uninsured, Medicare, ACA etc)

2. What kind of challenges have you run into as a result of high cost of care?

3. How do you discuss your cost of your treatment plan with your doctor? What about the cost of medications and procedures? Please elaborate (Probes: taking a list of questions/concerns to the visit, exploring options...)

4. If you are uncomfortable talking to your provider about costs, what could be done to change that?

5. What could make it easier for you to talk to your doctor? (Probes: attitudes, schedule, location...)

6. What could make it harder for you to talk to your doctor?

7. Can you think of anything else that might improve cost of care conversations between patients and health care providers?

8. Are there other thoughts you would like to share?

\section{${ }^{*}$ All questions were pilot tested Analysis}

All focus groups were audio-recorded, transcribed verbatim and checked for accuracy. All recording and transcriptions were free of identifying information. Data was analyzed using thematic and content analysis techniques as outlined by Bernard $(1996,2006)$, which identified emergent themes, or trends, from the focus group transcripts. As such, themes were developed from the data and not a priori. Thematic analysis involves observing data, recognizing it and attempting to understand it through encoding and interpretation. The computer software program ATLAS.ti (Scientific Software, 1999), a 
multifunctional qualitative data software program, was utilized to support the organization and analysis of the qualitative data. This program aided in the process of coding the transcripts and retrieving thematically- structured and ordered-text segments. The thematic analysis process involved: (1) producing a comprehensive inventory of important ideas, expressions, terms and phrases that reflect the language and views of participants, (2) generating categories under which identified ideas were placed, and (3) clustering the categories to identify broader themes and patterns that emerged from the data (Zemke \& Kramlinger, 1985). Five members of the research team participated in this data analysis process.

First, transcript data was in-vivo (line-by-line) coded independently by all 5 research team members to categorize responses. Each line of text was read and assigned a code. Codes were subsequently clustered to generate categories of data. Subcategories were constructed when needed. An open coding framework was used to aid in the process of code and category development. The lead author and coinvestigators independently coded the three focus group transcripts, and subsequently met to discuss any differences in the codes assigned to the text and to attain agreement about the coding process. After a thorough discussion about reasons for coding differences and correcting redundant coding, the research team came to an agreement about the coding assigned to lines of text and a final codebook was created. The final version of the codebook was utilized to re-code all the qualitative data. Categories of data were then combined to create over-arching themes and matrices were utilized to identify broader patterns and recurring themes across the three focus groups.

\section{Results}

Focus group participants included 27 older adults age 65+ (White $n=10$, African American $n=9$ and Hispanic/Latino $n=8)$. Most participants were female $(77.8 \%)$, had completed some college or were college graduates $(62.9 \%)$ and currently receive Medicare (100\%). While $0 \%$ of White focus group participants had an annual income of under $\$ 10,000$ (90\% had an income of greater than $\$ 30,000)$, and $0 \%$ of Hispanic/Latinos had an annual income under $\$ 10,000$ (50\% had an income of $\$ 10,000-\$ 19,000)$, $44 \%$ of African Americans had an income of $0-\$ 10,000$ per year. Sixty percent of White participants identified their health as excellent, compared to $44.4 \%$ of African Americans and $25 \%$ for Hispanic/Latinos. And while $90 \%$ of White participants had a second form of insurance in addition to Medicaid compared to $37.5 \%$ of Hispanic/Latinos, and no African Americans identified having another form of insurance. See Table 2 for a detailed description of study sample demographic characteristics. 
Table 2

Characteristics of Study Sample by Race ( $\mathrm{N}=27)$, Cost-of-care Survey Focus Group

\begin{tabular}{|c|c|c|c|c|}
\hline Characteristics & $\begin{array}{l}\text { Total } \\
\mathrm{N}=27 \text { (\%) }\end{array}$ & $\begin{array}{l}\text { White } \\
N=10 \text { (\%) }\end{array}$ & $\begin{array}{l}\text { Hispanic } \\
\mathrm{N}=8(\%)\end{array}$ & $\begin{array}{l}\text { African American/Black } \\
\mathrm{N}=9(\%)\end{array}$ \\
\hline \multicolumn{5}{|c|}{ Socio-demographic variables } \\
\hline \multicolumn{5}{|l|}{ Age } \\
\hline $65-69$ & $5(18.5)$ & - & $1(12.5)$ & $4(44.4)$ \\
\hline $70-74$ & $8(29.6)$ & - & $4(50.0)$ & $4(44.4)$ \\
\hline $75+$ & $14(51.85)$ & $10(100.0)$ & $3(12.5)$ & $1(11.1)$ \\
\hline \multicolumn{5}{|l|}{ Gender } \\
\hline Male & $6(22.2)$ & $4(40.0)$ & $1(12.5)$ & $1(11.1)$ \\
\hline Female & $21(77.8)$ & $6(60.0)$ & $7(62.5)$ & $8(88.8)$ \\
\hline \multicolumn{5}{|l|}{ Educational Level } \\
\hline Some high school/other & $2(7.4)$ & - & $1(12.5)$ & $1(11.1)$ \\
\hline High school & $8(29.6)$ & - & $3(37.5)$ & $5(55.6)$ \\
\hline Some college & $7(25.9)$ & $3(30.0)$ & $2(25.0)$ & $2(22.2)$ \\
\hline College/Graduate school & $10(37.0)$ & $7(70.0)$ & $2(25.0)$ & $1(11.1)$ \\
\hline \multicolumn{5}{|l|}{ Marital Status } \\
\hline Married & $12(44.4)$ & $5(50.0)$ & $5(62.5)$ & $2(22.2)$ \\
\hline Single & $5(18.5)$ & - & $1(12.5)$ & $4(44.4)$ \\
\hline Other & $10(37.0)$ & $5(50.0)$ & $2(25.0)$ & $3(33.3)$ \\
\hline \multicolumn{5}{|l|}{ Income } \\
\hline$\$ 0-\$ 9,999$ & $4(14.8)$ & - & - & $4(44.4)$ \\
\hline$\$ 10,000-\$ 19,999$ & $4(14.8)$ & - & $4(50.0)$ & - \\
\hline$\$ 20,000-\$ 29,999$ & $7(25.9)$ & $1(10.0)$ & $3(37.5)$ & $3(33.3)$ \\
\hline$\$ 30,000+$ & $12(44.4)$ & $9(90.0)$ & $1(12.5)$ & $2(22.2)$ \\
\hline \multicolumn{5}{|c|}{ Health and health insurance } \\
\hline \multicolumn{5}{|l|}{ Perceived Health Status } \\
\hline Excellent/Very Good & $12(44.4)$ & $6(60.0)$ & $2(25.0)$ & $4(44.4)$ \\
\hline Good & 9 (33.3) & $2(20.0)$ & $4(50.0)$ & $3(33.3)$ \\
\hline
\end{tabular}




\begin{tabular}{|c|c|c|c|c|}
\hline Characteristics & $\begin{array}{l}\text { Total } \\
\mathrm{N}=27(\%)\end{array}$ & $\begin{array}{l}\text { White } \\
N=10 \text { (\%) }\end{array}$ & $\begin{array}{l}\text { Hispanic } \\
N=8(\%)\end{array}$ & $\begin{array}{l}\text { African American/Black } \\
\mathrm{N}=9(\%)\end{array}$ \\
\hline Fair/Poor & $6(22.2)$ & $2(20.0)$ & $2(25.0)$ & $2(22.2)$ \\
\hline \multicolumn{5}{|c|}{ High Blood Pressure } \\
\hline Yes & $15(55.6)$ & $5(50.0)$ & $6(75.0)$ & $4(44.4)$ \\
\hline No & $12(44.4)$ & $5(50.0)$ & $2(25.0)$ & $5(55.6)$ \\
\hline \multicolumn{5}{|l|}{ Diabetes } \\
\hline Yes & $11(40.7)$ & $2(20.0)$ & $6(75.0)$ & 3 (33.3) \\
\hline No & $16(59.3)$ & $8(80.0)$ & $2(25.0)$ & $6(66.7)$ \\
\hline \multicolumn{5}{|l|}{ Heart Disease } \\
\hline Yes & $6(22.2)$ & $3(30.0)$ & $2(25.0)$ & $1(11.1)$ \\
\hline No & $21(77.8)$ & $7(70.0)$ & $6(75.0)$ & $8(88.8)$ \\
\hline \multicolumn{5}{|c|}{ Other Chronic Conditions } \\
\hline Yes & $11(40.7)$ & $6(60.0)$ & $2(25.0)$ & $3(33.3)$ \\
\hline No/Missing & $16(59.3)$ & $4(40.0)$ & $6(75.0)$ & $6(66.7)$ \\
\hline \multicolumn{5}{|l|}{ Medicare } \\
\hline Yes & $27(100.0)$ & $10(100.0)$ & $8(100.0)$ & $9(100.0)$ \\
\hline \multicolumn{5}{|l|}{ Medicaid } \\
\hline Yes & $4(14.8)$ & - & $3(37.5)$ & $1(11.1)$ \\
\hline No/Missing(3) & $23(85.2)$ & $10(100.0)$ & $5(62.5)$ & $8(88.8)$ \\
\hline \multicolumn{5}{|l|}{ Other Insurance } \\
\hline Yes & $12(44.4)$ & $9(90.0)$ & $3(37.5)$ & - \\
\hline No/Missing & $15(55.6)$ & $1(10.0)$ & $5(62.5)$ & $9(100.0)$ \\
\hline
\end{tabular}

\section{Focus Group Results}

Results of thematic analysis yielded four over-arching themes: 1) Occurrence of Cost-of-care Conversations, 2) Contributors to Cost-of-care Conversations, 3) Barriers to Cost-of-care Conversations and 4) Strategies to Enhance Cost-of-care Conversations. The following paragraphs highlight key quotes from study participants that reflect the identified themes. Also refer to Table 3 for a more thorough listing 
of participant quotes in relation to the identified themes. We first identify the similarities with regard to each theme across the three focus groups, and then identify racial/ethnic differences within each theme.

Table 3. Cost of Care Results Table 


\section{Themes Details}

\section{1) Occurrence of Cost-of- care Conversations}

"It's just not discussed. That's just something that doesn't occur. A procedure or whatever-you don't see it. You don't know. It was what it was. You don't know what the price is and it just happens. We're there to get the treatment, and price is not something to be discussed. Either you have regular insurance or Medicaid and Medicare and we never discuss the price. It should be discussed."

"Sometimes you do better with the PA [physician assistant] than you do with the physician because they seem to have better listening skills.

"There are times when a pharmacist can better prescribe for you than a doctor."

"I did talk to a dentist when I went... I was kind of shocked at how much it was, and he actually did take a little off."

"I've talked to the pulmonary hypertension person about cost of this med but mainly from my point of view that I think it's ludicrous that they're charging so much and it's going up so high... And he agrees."

"I don't think that's a thing that the doctors have been taught, just like nutrition. They don't know anything about nutrition. Most of them, let's say. Uh, they don't seem to discuss finances you know when it comes the medicines and the cost of the procedures. And apparently, they don't think that that's their job to do."

"They are there to check you, and prescribe, and good-bye,"

"Well I don't think the doctor's job to tell us how much it costs. He's a doctor to take care of us there. He's got a billing department and he's got his secretaries. They should be the ones to inform us. The doctors, they are there to take care of us."

"[Doctors] should be explaining it to you while you're sitting down telling you all of what needs to be done and what you need to do and how you need to prepare yourself, and this is the list of the prices you're gonna have to pay and get ready for, you know, so you can have an idea. We shouldn't have to do that. They should bring it to us while they're talking to us to let us know what we're going up against, whether it's big or small. The patient should always know-shouldn't have to ask the doctor."

\section{2) Contributors to Cost-of- care Conversations}

"I think it's the attitude of the doctor because you can go into a doctor's office and they'll almost push you out the door. Some doctors you can sit back... The doctor I go now we sit there, and we talk for at least about 45 minutes. Some doctors-they don't want you to talk to them... But I think it's the attitude of the doctor."

"If the doctor is friendly. If they are unfriendly you can go to the doctor, I don't even want to see them again. But you go to a friendly doctor and they make you feel comfortable. They know you're uncomfortable, so they work with you and before you know it you are working with them and talking to them. And I think it all depends on the doctor."

"[my doctor is] very approachable. I feel that I can sit back and talk with him about anything."

"If they're not approachable, then he's not the doctor for me."

"When I go to my doctor, usually they meet you at a hub. It makes me feel comfortable because I can talk about anything that may come to my mind. I feel very comfortable with my doctor." 
"I don't like switching doctors. I like to go to a doctor and stay with that doctor. Once I get to know him or her, then I'm comfortable. If something happens and it tells me that I don't need to continue going there, then I do that. In most cases I stick with the same doctor until they retire or whatever."

"If you have confidence in your doctor, I don't think there's anything that you should hold back, and probably wouldn't, if you had an ailment that you wanted them to examine. But if you don't have confidence in the doctor, you're in trouble to start with."

\section{3) Barriers to Cost-of-care Conversations}

"The old-time country doctor and bedside manner you know has sort of gone out the window."

"We are used to real doctors."

"When you were talking about seniors and thinking differently-l think all of us had the old kind of checkup. So, the new people coming out don't know what a checkup used to be. They just think asking these questions is what you do. So, when they're dealing with older people and people our age, we're used to having a real doctor's appointment."

"Well our physicians have not had training in that area."

"Seniors are not... I'm sure you'll know when you get to be one... They have odd problems. We think differently. We've been around the block several times. We are very opinionated. I speak for myself, and I think the doctors have to know us, understand our idiosyncrasies, be prepared to deal with them. I think that'll do more than medicine will."

"[physicians name] kept me waiting 45 minutes on Monday, and the nurse and the clerk told me 'please tell him that you're not happy'. I said, 'I'm furious'. I'm 83 years old and I don't have a lot of time to waste."

"I feel it's a lack of respect for the patient. I mean we're important too regardless. So, that's the one biggest complaint I have is the amount of time I have to wait."

"I think the time-sometimes a physician feels really pressured. I had a referral to someone; she came in with her tablet, sat down, and typed madly away for ten minutes, asked me a couple questions for five minutes and left after I had waited for her for 40 minutes. And I would tell you I would not see or recommend that physician again."

“Sometimes people don't want to go to the doctor because the doctor doesn't speak your language."

"You want to make sure that you can go to a doc that can communicate with you in a language that you understand. Cause you know, even if you bring an interpreter, sometimes the interpreter doesn't know the right terminology to translate to the other person. So, if you have a doctor that can speak to you directly in your language then it's much better."

"Yeah if you have a female you feel more comfortable. I mean I had three pregnancies and my first two pregnancies went through female, and I was very comfortable with them. You know, I can tell them everything. But it's true, when you have a male, its different. You can't really say everything you want to tell them."

"I just don't like doctors. I say, I just don't like doctors." He went on to say, "When I was a little boy, I thought the doctor was trying to kill me." 
"When I had to go to the doctor it's like a little shock when something is wrong. So, you're very wary of doctors. When I go in, my blood pressure will go up like maybe ten notches and one of the nurses told me I had what they call white coat syndrome."

"The holy church I was brought up in-they teach you faith in God and prayer and believing... because of my background that's the way I am. I don't take medication. They said, 'we know you don't take any of that, so we'll give you some vitamin C'. It's still in the refrigerator now. I don't put nothing in my body. To me... I think that's the way to keep you sick. People die and they don't know what's going on because the doctor doesn't really know what's going on. They're practicing. When they give you stuff they're making money and practicing. They don't really know, they're practicing."

\title{
4) Strategies to Enhance Cost-of-care Conversations
}

\begin{abstract}
"Mine send a brochure out and they have the copayments and everything for you when you go there once you get yourself situated so you don't get in a jam. They take care of everything, so I don't have that discussion. I know I'm supposed to pay this copayment. So, they send something through the mail, and then I just send them the payment. As long as I'm feeling good, and I try hard to keep feeling good. I'm fine."

"We already said it, change doctors."

"We spend a lot of time waiting for the doctor to come into the office. Last time I was in the office, I noticed, on the wall, they had a list of questions you might want to ask your doctor. So maybe to improve the discussion about costs of healthcare, that could be part of what is posted there. You know some of the questions that you might have about your care might include cost."
\end{abstract}

\section{Occurrence of Cost-of-care Conversations}

Overall, focus group participants suggested that cost-of-care conversations are not happening. Among all racial and ethnic groups, participants often stated that they do not talk to their health care providers about the costs of medical care/treatments. While almost all participants stated that they do not have cost-of-care conversations with their physicians, participants talked about having cost-of-care conversations with other provider types. Most commonly these conversations occurred with pharmacists, physician assistants or dentists. Some participants suggested that these other providers were better than physicians, largely due to them making more time to have conversations with their patients. One participant stated, "Sometimes you do better with the PA [physician assistant] than you do with the physician because they seem to have better listening skills." One participant suggested that after having a cost-of-care conversation with their dentist, that their bill was reduced.

Although participants agreed that they do not discuss cost of medical care with their physicians, all three racial/ethnic groups talked about having conversations with providers about the cost of prescription medications. While these conversations sometimes occurred with physicians, most participants stated these conversations occurred with a pharmacist. Some participants felt that physicians are largely unaware of the issue of cost-of-care conversations and that this may be why these conversations are not broached. For example, "I don't think that's a thing that the doctors have been taught, just like nutrition. They don't know anything about nutrition. Most of them, let's say. Uh, they don't seem to discuss finances you know when it comes the medicines and the cost of the procedures. And apparently, they don't think 
that that's their job to do." Focus group participants discussed at length whether or not these conversations should actually be occurring with physicians and there was some disagreement about this. Some participants felt having these conversations is not a physician's job. One participant stated, "Well I don't think the doctor's job to tell us how much it costs. He's a doctor to take care of us there. He's got a billing department and he's got his secretaries. They should be the ones to inform us. The doctors, they are there to take care of us." Other participants, however felt these conversations are important and should be had with physicians.

\section{Racial/ethnic Differences in Cost-of-care Conversations}

Thematic analysis revealed very few racial/ethnic differences with regard to this theme. All racial/ethnic groups had similar experiences with the lack of cost-of-care conversations with providers. White focus group participants were more likely to identify other providers with whom they have cost-of-care conversations with. Hispanic/Latino participants were more likely to believe that having cost-of-care conversations was not the role of the physician, while African Americans focus group participants were more likely to suggest that it should be the role of a physician. White focus group participants also discussed talking with providers about homeopathic medicine and alternative treatment options, which was not brought up by Hispanic/Latino and African Americans participants.

Contributors to Cost-of-care Conversations

Focus group participants talked in depth about contributors to cost-of-care conversations. Across all racial and ethnic groups, the most commonly identified contributors included provider affect, rapport/relationship building and communication/collaboration. Provider affect or attitude was commonly brought up by focus group participants, who suggested that providers with a positive affect led to better relationships and more in-depth conversations which ultimately enhanced their service utilization. Having a friendly affect was mentioned specifically as an important contributor. One participant stated, "If the doctor is friendly. If they are unfriendly you can go to the doctor, I don't even want to see them again. But you go to a friendly doctor and they make you feel comfortable. They know you're uncomfortable, so they work with you and before you know it you are working with them and talking to them. And I think it all depends on the doctor." Being approachable also seemed to make a big difference for participants, for example, "[my doctor is] very approachable. I feel that I can sit back and talk with him about anything." Another participant emphasized this point by stating, "If they're not approachable, then he's not the doctor for me."

In addition to affect, having a good rapport or relationship with a provider was suggested to increase the likelihood of having important conversations. Being comfortable with your provider seemed to be very important to focus group participants. This comfortability and relationship often meant patients would stay with their doctor for a long period of time, thus enhancing this relationship and increasing the likelihood of difficult to have conversations. An important component to developing a strong rapport and relationship with a provider was communication and collaboration. Participants were more likely to 
identify having a good relationship and rapport with their provider, when they also felt their provider was easy to communicate with and that they were collaborating with their provider on their treatment plan.

\section{Racial/Ethnic Differences in Contributors to Cost-of-care Conversations}

Thematic analysis revealed very few racial/ethnic differences with regard to this theme. All racial/ethnic groups had similar perceptions about what can contribute to cost-of-care conversations with providers. White focus group participants however, also discussed the importance of having confidence in your provider, an issue not brought up in the African American and Hispanic/Latino groups. One participant stated, "If you have confidence in your doctor, I don't think there's anything that you should hold back, and probably wouldn't, if you had an ailment that you wanted them to examine. But if you don't have confidence in the doctor, you're in trouble to start with." Multiple White focus group participants suggested that having confidence in your doctor was a key component to having important conversations, as well as having positive clinical outcomes. A few suggested that if you do not have confidence in your provider, the best solution may be to find a new doctor.

\section{Barriers to Cost-of-care Conversations}

Barriers to cost-of-care conversations were frequently brought up by focus group participants. Barriers identified by focus group participants included: new age doctors, lack of physician training, wait time, lack of focus on the patient, language, provider preferences, fear of physicians and religion. There was very little similarity across racial and ethnic groups with regard to this theme. White and Hispanic/Latino focus group participants both discussed how health care has had changes in the past few decades, and that this "new age healthcare" creates barriers to cost-of-care conversations. One participant stated, "The old-time country doctor and bedside manner you know has sort of gone out the window." Participants suggested that these "new" doctors do not know how to communicate with their patients and these quick appointments do not allow time for further conversations. One participant stated, "When you were talking about seniors and thinking differently-l think all of us had the old kind of checkup. So, the new people coming out don't know what a checkup used to be. They just think asking these questions is what you do. So, when they're dealing with older people and people our age, we're used to having a real doctor's appointment."

This issue was related to a lack of physician training, which was an issue that came up in the White and African American focus groups. Participants suggested that doctors are not receiving the appropriate training, which creates barriers to important conversations. When asked why they do not have cost-ofcare conversations with their physician, one participant stated, "Well our physicians have not had training in that area." Other participants suggested that in addition to lack of training in having cost-of-care conversations, that physicians are not well trained to work with older adults.

Racial and Ethnic Differences in Barriers to Cost-of-care Conversations 
There were a range of other barriers to cost-of-care conversations that were brought up in individual focus groups. For White focus group participants, wait time was an issue that was discussed repeatedly. Focus group participants felt that they are often made to wait inappropriately long times to see their doctor, which can impact their relationship with their doctor and prevents important conversations from occurring. One participant stated, "[physicians name] kept me waiting 45 minutes on Monday, and the nurse and the clerk told me 'please tell him that you're not happy'. I said, 'I'm furious'. I'm 83 years old and I don't have a lot of time to waste." They continued their thoughts with, "I feel it's a lack of respect for the patient. I mean we're important too regardless. So, that's the one biggest complaint I have is the amount of time I have to wait."

Another barrier brought up in the White focus group was the lack of focus on the patient. Participants were particularly sensitive to the issue of feeling not attended to and not being the focus of their physician's attention. When asked what might prevent them from having a cost-of-care conversation with their physician, one participant stated: "I think the time-sometimes a physician feels really pressured. I had a referral to someone; she came in with her tablet, sat down, and typed madly away for ten minutes, asked me a couple questions for five minutes and left after I had waited for her for 40 minutes. And I would tell you I would not see or recommend that physician again." Overall, for White focus group participants, their physician "being in a hurry," being "distracted," or otherwise not paying attention to them during their appointment was the most frequently identified barrier.

For Hispanic/Latino focus group participants, the most frequently identified barriers were language and provider preferences. For many participants, they identified language barriers with their providers. Having a provider not fluent in one's native language, can deter patients from going to the doctor in general. One participant stated, "Sometimes people don't want to go to the doctor because the doctor doesn't speak your language." Language can also inhibit the rapport/relationship building process and can be a barrier to having important conversations. For example, "You want to make sure that you can go to a doc that can communicate with you in a language that you understand. Cause you know, even if you bring an interpreter, sometimes the interpreter doesn't know the right terminology to translate to the other person. So, if you have a doctor that can speak to you directly in your language then it's much better." This led to a discussion about preferences for providers, of which having a provider who speaks your native language was top of the list. Another preference discussed in only the Hispanic/Latino focus group was the issue of gender preference. Female participants suggested that they would be less likely to have certain conversations with their provider if they were male

For African American focus group participants, the most frequently identified barriers were fear and religion. The issue of fear of doctors only came up in the focus group with African American participants. Multiple participants discussed not being fully trusting of the healthcare profession and of doctors. One participant stated, "I just don't like doctors. I say, I just don't like doctors." Another participant stated that going to see a doctor actually makes them sick. They went on to say, "When I had to go to the doctor it's like a little shock when something is wrong. So, you're very wary of doctors. When I go in, my blood pressure will go up like maybe ten notches and one of the nurses told me I had what they call white coat 
syndrome." This "white coat syndrome" can impact the ability to communicate and build a relationship with a provider, thus creating a barrier to important clinical and cost-of-care related conversations. Religion as barrier was also addressed in only the African American focus group. One participant felt so strongly about their belief in God and prayer, that this not only deterred cost-of-care conversations, but also deterred them from taking any pharmaceutical treatments and led to mistrust in their provider.

Strategies to Enhance Cost-of-care Conversations

Although this was not specifically asked of focus group participants, many offered up suggestions inductively about what might increase the likelihood of cost-of-care conversations.

Some participants suggested that a poster on the wall in the doctor's office reminding patients to talk to their doctor about the cost of health care might be effective. Other participants suggested sending home brochures with patients to discuss health care costs and providing them with sample questions they might want to talk to their doctor about. These strategies empower the patient to address concerns with their doctor directly. Some participants felt that it was important for patients to advocate for themselves, and to become health literate so they would not need to rely on their doctors for answers to their questions. Lastly, some participants felt that if you have a doctor that you do not feel you can have important conversations with, the best strategy is to get a new doctor.

\section{Discussion}

To date, there is little research on cost-of-care $(\mathrm{CoC})$ conversations among the elderly in Florida, a bellwether state for issues related to aging. In an effort to fill this gap, this study conducted race/ethnicity stratified focus groups with a diverse sample of older adults to discuss participant experiences with costof-care conversations and to look at racial/ethnic differences in experiences and perceptions. Our analysis yielded four overarching themes that we have discussed in depth using participant quotes to demonstrate and emphasize key points.

In our sample, $\mathrm{CoC}$ conversations between patients and physicians were not occurring in all three focus groups, and there were very few racial/ethnic differences. This finding is consistent with previous research that suggests while $70-80 \%$ of elderly patients want to discuss cost-of-care with their doctors; only 30-40\% report having these conversations (Hunter et al., 2016; Riggs \& Ubel, 2014; Schmittdiel et al., 2010). While previous research has not sufficiently explained this occurrence, findings from the current study may shed some light on this. In the current study, focus group participants believed that physicians are largely unaware of the costs of healthcare and are not trained to have these conversations with patients. This lack of awareness and training may help explain why these conversations are not occurring, in spite of research that suggests cost-of-care conversations between patients and doctors is one of the recommended approaches to controlling health care costs and alleviating patients' financial burden of care. Also consistent with previous research (Hardee et al., 2005), our findings suggest that while some participants do not believe it is the responsibility of physicians to have cost-of-care 
conversations with patients, the majority of focus group participants believe they should be occurring and should be initiated by their provider.

Results from our focus groups suggest that there are a number of barriers which deter these conversations from occurring. New age physicians, long wait times, lack of focus on the patient, language, provider preferences, fear of physicians, and religion were all identified inductively in these focus groups as deterrents to cost-of-care conversations. Research suggests that racial/ethnic minorities and low-income patients are less likely than their counterparts to trust their doctor to inform them about the costs of different treatment options (Long et al., 2017). Our findings are consistent with this research, as issues of fear and mistrust were most frequently discussed by African American and Hispanic/Latino participants. The barriers identified by participants also impact the ability to develop strong rapport and relationships with providers, which was identified as a potential contributor to cost-of-care conversations.

Research suggests that Medicare beneficiaries, especially African Americans and Hispanics, often lack the skills and knowledge to successfully use their health insurance benefits and make decisions about their care (McCormack et al., 2009; Paez et al., 2014). Our findings are consistent with this research. African American and Latino Hispanic participants talked in depth about the importance of advocating for yourself and developing medical literacy in order to be able to ask informed questions and to not be forced to rely on your provider for knowledge.

The limitations of this study must be taken into consideration when reviewing our findings. The limitations of a purposive sample are recognized (i.e., lack of generalizability of findings, potential selection bias etc.). We found for example that the White focus group participants were substantially healthier and more financially secure than the African American and Hispanic/Latino study participants, and were more likely to have a secondary form of insurance in addition to Medicare, which may have contributed to some of the different experiences identified in the focus groups. Further, this is also a small cross-sectional study, and as such we are unable to capture attitudes and beliefs over time. However, given that there are few previously reported qualitative studies that examine the contextual factors that influence cost-of-care conversations in a diverse sample of older adults, these findings represent an important contribution to the literature.

\section{Conclusion And Implications}

The results of this qualitative study suggest that cost-of-care conversations are not occurring between providers and their patients. A number of barriers, contributors, and solutions to cost-of-care conversations were identified by focus group participants, which have important implications for the field. First, it is important that healthcare providers are made aware of the distinct barriers (e.g., long wait times, a lack of focus on their patient, and an attitude) to cost-of-care conversations among older patients. These concerns can lead to stress which exacerbates both physical and mental health conditions (Delgado-Guay et al., 2015). Second, as most patients have a preference for their provider to initiate these conversations, it is critical for physicians to have the tools and training to successfully discuss cost of 
care with older patients. Participants indicated language fluency and gender preferences. Cultural competency training, cultural humility and provider awareness of patient preferences and expectations, may be important to enhance rapport and enhance these important conversations. Finally, study participants provided suggestions including posters located in doctor's offices and brochures sent home to patients which may facilitate cost-of-care conversations. Future research studies are needed to pilot test these strategies to determine whether they lead to an increase in cost-of-care conversations and enhance the rapport between providers and patients.

\section{Abbreviations}

$\mathrm{CoC}$

Cost of Care

\section{Declarations}

Ethics approval and consent to participate: This study (Pro00036171) received approval from our University's Institutional Review Board. All participants provided written informed consent prior to engaging in the research.

Consent for publication: Not applicable as all study participant info is de-identified

Availability of data and materials: The datasets used and/or analyzed during the current study are available from the corresponding author on reasonable request.

Competing interests: The authors declare that they have no competing interests

Funding: This work was supported by an internal award from the College of Public Health at the University of South Florida. Funder provided financial support for the conduct of the research, but had no other role in the research process.

Authors' contributions: $\mathrm{KC}$ analyzed all focus group transcripts and lead the thematic analysis process, which involved interpretation of results and took the lead on writing the manuscript. JW conceptualized the study, conducted focus groups, participated in all qualitative analysis and interpretation of results and assisted with writing the manuscript. ECG aided in the conceptualization of the study, conducted focus groups, translated data from Spanish to English, participated in all qualitative analysis and interpretation of results and assisted with writing the manuscript. BLO participated in all qualitative analysis and interpretation of results and was a major contributor in writing the manuscript. EA participated in all qualitative analysis and interpretation of results and assisted with writing and editing the manuscript. IC participated in all qualitative analysis and interpretation of results and assisted with writing and editing the manuscript. $A G(1)$ assisted with writing and editing the manuscript, developed all tables for the manuscript, and assisted with interpretation of results. $A G(2)$ assisted with writing and editing the 
manuscript, pulled meaningful quotes for table development, and assisted with interpretation of results. All authors read and approved the final manuscript.

Acknowledgements: Not applicable

\section{References}

1. Attanasio OP, Emmerson C. Mortality, health status, and wealth. J Eur Econ Assoc. 2003;1(4):82150. https://doi.org/10.1162/154247603322493168.

2. Bernard HR. Qualitative data, quantitative analysis. Field Methods. 1996;8(1):9-11. https://doi.org/10.1177/1525822x960080010401.

3. Bernard HR. (2006). Research methods in anthropology: Qualitative and quantitative approaches (4th ed.). Altamira Press.

4. Blumenthal D, Davis K, Guterman S. Medicare at 50 - Origins and evolution. N Engl J Med. 2015;372(5):479-86. https://doi.org/10.1056/nejmhpr1411701.

5. Briesacher BA, Ross-Degnan D, Wagner AK, Fouayzi H, Zhang F, Gurwitz JH, Soumerai SB. Out-ofpocket burden of health care spending and the adequacy of the Medicare Part D low-income subsidy. Med Care. 2010;48(6):503-9. https://doi.org/10.1097/mlr.0b013e3181dbd8d3.

6. Chen J, Rizzo JA, Ortega AN. Racial and ethnic differences in drug expenditures and access under Medicare Part D. J Health Care Poor Underserved. 2011;22(3):1059-74. https://doi.org/10.1353/hpu.2011.0070.

7. Cubanski J, Neuman T. (2017). The facts on Medicare spending and financing key facts. In Issue Brief. The Henry J. Kaiser Family Foundation. http://files.kff.org/attachment/Issue-Brief-The-Factson-Medicare-Spending-and-Financing.

8. Cubanski J, Swoope C, Damico A, Newman T. (2014). Health care on a budget: The financial burden of health spending by Medicare households. The Henry J. Kaiser Family Foundation. https://www.kff.org/medicare/issue-brief/health-care-on-a-budget-the-financial-burden-of-healthspending-by-medicare-households/.

9. Cubanski J, Swoope C, Boccuti C, Casillas G, Griffin S, Neuman T. (2015). A primer on Medicare: Key facts about the Medicare program and the people it covers. The Henry J. Kaiser Family Foundation. https://www.kff.org/medicare/report/a-primer-on-medicare-key-facts-about-the-medicare-programand-the-people-it-covers/.

10. Davis K, Guterman S, Bandeali F. (2015). The Affordable Care Act and Medicare: How the law is changing the program and the challenges that remain. The Commonwealth Fund. https://www.commonwealthfund.org/publications/fund-reports/2015/jun/affordable-care-act-andmedicare.

11. Delgado-Guay M, Ferrer J, Rieber AG, Rhondali W, Tayjasanant S, Ochoa J, Cantu H, Chisholm G, Williams J, Frisbee-Hume S, Bruera E. Financial distress and its associations with physical and 
emotional symptoms and quality of life among advanced cancer patients. Oncologist. 2015;20(9):1092-8. doi:10.1634/theoncologist.2015-0026.

12. De Nardi M, French E, Jones JB. Why do the elderly save? The role of medical expenses. J Polit Econ. 2010;118(1):39-75. doi:10.1086/651674.

13. Gerteis J, Izrael D, Dietz D, LeRoy L, Ricciardi R, Miller T, Basu J. (2014). Multiple chronic conditions chartbook 2010 medical expenditure panel survey data (AHRQ Pub. No. 14-0038). U.S. Department of Health and Human Services, Agency for Healthcare Research and Quality. https://www.ahrq.gov/sites/default/files/wysiwyg/professionals/prevention-chroniccare/decision/mcc/mccchartbook.pdf.

14. Gould E, Cooper D. (2013). Financial security of elderly Americans at risk (EPI Briefing Paper \#362). Economic Policy Institute. https://files.epi.org/2013/financial-security-elderly-americans-risk.pdf.

15. Hardee JT, Platt FW, Kasper IK. Discussing health care costs with patients. J Gen Intern Med. 2005;20(7):666-9. https://doi.org/10.1111/j.1525-1497.2005.0125.x.

16. Hunter WG, Hesson A, Davis JK, Kirby C, Williamson LD, Barnett JA, Ubel PA. Patient-physician discussions about costs: Definitions and impact on cost conversation incidence estimates. BioMed Central Health Services Research. 2016;16(108):1-12. https://doi.org/10.1186/s12913-016-1353-2.

17. Jacobson G, Griffin S, Neuman T, Smith K. (2017). Income and assets of Medicare beneficiaries, 2016-2035 (Issue Brief). The Henry J. Kaiser Family Foundation. https://www.kff.org/medicare/issue-brief/income-and-assets-of-medicare-beneficiaries-2016-2035/.

18. Kelley AS, McGarry K, Gorges R, Skinner JS. The burden of health care costs for patients with dementia in the last 5 years of life. Ann Intern Med. 2015;163(10):729-36. https://doi.org/10.7326/m15-0381.

19. Knickman JR, Snell EK. The 2030 problem: Caring for aging baby boomers. Health Serv Res. 2002;37(4):849-84. https://doi.org/10.1034/j.1600-0560.2002.56.x.

20. Komisar H, Cubanski J, Dawson L, Neuman T. (2012, March). Key issues in understanding the economic and health security of current and future generations of seniors (Issue Brief \#8289). The Henry J. Kaiser Family Foundation. https://www.kff.org/wp-content/uploads/2013/01/8289.pdf.

21. Krueger RA, Casey MA. (2000). Focus groups: A practical guide for applied research (3rd ed.). Sage Publications.

22. $10.1377 / \mathrm{hblog} 20170922.062078 /$ full/

Long S, Bart L, Hempstead K. (2017, September 22). Patient-centered care starts with patient-provider communication. Health Affairs Blog. https://www.healthaffairs.org/do/10.1377/hblog20170922.062078/full/.

23. McCormack L, Bann C, Uhrig J, Berkman N, Rudd R. Health insurance literacy of older adults. J Consum Aff. 2009;43(2):223-48. https://doi.org/10.1111/j.1745-6606.2009.01138.x.

24. Meschede T, Shapiro TM, Sullivan L, Wheary J. (2010). Severe financial insecurity among AfricanAmerican and Latino seniors (Report \#3). The Institute on Assets and Social Policy. 
https://heller.brandeis.edu/iasp/pdfs/racial-wealth-equity/llol/severe-financial-insecurity-africanamerican-latino.pdf.

25. Osborn R, Moulds D, Squires D, Doty MM, Anderson C. International survey of older adults finds shortcomings in access, coordination, and patient-centered care. Health Aff. 2014;33(12):2247-55. https://doi.org/10.1377/hlthaff.2014.0947.

26. Paez KA, Mallery CJ, Noel H, Pugliese C, McSorley VE, Lucado JL, Ganachari D. Development of the Health Insurance Literacy Measure (HILM): Conceptualizing and measuring consumer ability to choose and use private health insurance. Journal of Health Communication. 2014;19(sup2):225-39. https://doi.org/10.1080/10810730.2014.936568.

27. Rahimi AR, Spertus JA, Reid KJ, Bernheim SM, Krumholz HM. Financial barriers to health care and outcomes after acute myocardial infarction. J Am Med Assoc. 2007;297(10):1063-72. https://doi.org/10.1001/jama.297.10.1063.

28. Riggs KR, Ubel PA. Overcoming barriers to discussing out-of-pocket costs with patients. Journal of the American Medical Association Internal Medicine. 2014;174(6):849-50. https://doi.org/10.1001/jamainternmed.2014.853.

29. Schmittdiel JA, Steers N, Duru OK, Ettner SL, Brown AF, Fung V, Hsu J, Quiter E, Tseng C-W, Mangione CM. Patient-provider communication regarding drug costs in Medicare Part $D$ beneficiaries with diabetes: A TRIAD Study. BioMed Central Health Services Research. 2010;10(164):1-7. https://doi.org/10.1186/1472-6963-10-164.

30. Schoenberg NE, Kim H, Edwards W, Fleming ST. Burden of common multiple-morbidity constellations on out-of-pocket medical expenditures among older adults. Gerontologist. 2007;47(4):423-37. https://doi.org/10.1093/geront/47.4.423.

31. Wallace GL, Haveman R, Wolfe B. Health status, health shocks, and asset adequacy over retirement years. Research on Aging. 2017;39(1):222-48. doi:10.1177/0164027516669567.

32. Wilson IB, Schoen C, Neuman P, Strollo MK, Rogers WH, Chang H, Safran DG. Physician-patient communication about prescription medication nonadherence: A 50-state study of America's seniors. J Gen Intern Med. 2007;22(1):6-12. https://doi.org/10.1007/s11606-006-0093-0.

33. Wiltshire JC, Elder K, Kiefe C, Allison JJ. Medical debt and related financial consequences among older African American and White adults. Am J Public Health. 2016;106(6):1086-91. https://doi.org/10.2105/ajph.2016.303137.

34. Zemke R, Kramlinger T. (1985). Figuring things out: A trainer's guide to needs and task analysis. Addison-Wesley.

35. Zilcha I, Schneier N. Out-of-pocket health expenditures: A suggested role for social security. Risk Management Insurance Review. 2012;15(2):153-64. https://doi.org/10.1111/j.15406296.2012.01215.x.

\section{Supplementary Files}


This is a list of supplementary files associated with this preprint. Click to download.

- ConnerManuscriptCOREQChecklist.pdf 